\title{
Analisis Pengendalian Kualitas Produk Cacat pada Lensa Tipe X Menggunakan Lean Six Sigma dengan Konsep DMAIC
}

\author{
Ida Rinjani $^{\left.1^{*}\right)}$, Wahyudin Wahyudin ${ }^{2)}$, Billy Nugraha ${ }^{3)}$ \\ *Jurusan Teknik Industri, Fakultas Teknik, Universitas Singaperbangsa Karawang, Jl. H.S. Ronggowaluyo \\ Telukjambe Timur, Karawang -41361, Indonesia \\ 1)idarinjani19@gmail.com \\ ${ }^{2}$ hwwahyudin@gmail.com \\ ${ }^{3)}$ billynugraha982@gmail.com
}

\begin{abstract}
Abstrak. Salah satu metode untuk meningkatkan kualitas adalah Lean Six Sigma dengan konsep DMAIC (Define, Measure, Analyze, Improve dan Control). Hal ini berorientasi hanya akan ada 3,4 cacat produk dari setiap 1 juta produk yang diproduksi. Penelitian ini bertujuan untuk meningkatkan kualitas produk lensa di PT. XYZ, terutama lensa tipe x yang sering terjadi cacat produk. Hasil penelitian menunjukan, ada 9 (sembilan) jenis cacat produk pada lensa tipe x selama periode Desember 2019. Diantaranya: Bubble, Mold Derty, Thicknes Out, Edge Problem, Crack, Rellease, Lint, Scratches dan Prishm. Dari hasil perhitungan didapatkan rata-rata level sigma yaitu 5,3 dengan nilai rata-rata DPMO sebesar 242. Berdasarkan diagram pareto, perbaikan diprioritaskan pada 3 (tiga) jenis cacat yang paling dominan. Yaitu jenis defect Bubble dengan persentase cacat 52\%, Thicknes Out 30\% dan Mold Derty 10\%. Kemudian dilakukan analisis sebab akibat menggunakan fishbone, diketahui bahwa faktor manusia, material, tools, mesin, lingkungan dan metode menjadi faktor penyebab terjadinya ketiga jenis cacat. Tahap improvement dilakukan usulan perbaikan menggunakan metode $5 \mathrm{~W}+1 \mathrm{H}$ sebagai bentuk perbaikan dalam peningkatan kualitas.
\end{abstract}

Kata kunci: Cacat, Six Sigma, DMAIC

\begin{abstract}
Quality Control Analysis of Product Defects in the Lens of Type X Using the Lean Six Sigma Concept with DMAIC]. One method to improve quality is Lean Six Sigma with the concept of DMAIC (Define, Measure, Analyze, Improve and Control). It is oriented that there will only be 3.4 product defects for every 1 million products produced. This study aims to improve the quality of lens products at PT. XYZ, especially x-type lenses where product defects often occur. The results showed that there were 9 (nine) types of product defects in type x lenses during the period of December 2019. Among them: Bubble, Mold Derty, Thicknes Out, Edge Problem, Crack, Rellease, Lint, Scratches and Prishm. From the calculation results, the average sigma level is 5.3 with an average DPMO value of 242. Based on the Pareto diagram, repairs are prioritized on the 3 (three) most dominant types of defects. Namely the Bubble defect with a defect percentage of 52\%, Thicknes Out $30 \%$ and Mold Derty 10\%. Then performed a cause and effect analysis using a fishbone, it is known that human factors, materials, tools, machines, environment and methods are the factors causing the three types of defects. The improvement stage is carried out with improvement proposals using the $5 \mathrm{~W}+1 \mathrm{H}$ method as a form of improvement in quality improvement.
\end{abstract}

Keywords: Defect, Six Sigma, DMAIC

\section{Pendahuluan}

PT. XYZ merupakan perusahaan yang memproduksi berbagai jenis lensa, khususnya lensa untuk kacamata fashion. Produk lensa yang dihasilkan merupakan lensa (produk jadi) yang siap didistribusikan pada berbagai perusahaan yang memproduksi kacamata, baik lokal, regional, maupun internasional. Dalam hal ini, PT. XYZ bertindak sebagai penyedia atau supplier lensa jadi untuk kembali dijual pada perusahaan lain yang memproduksi kacamata. Sistem produksi yang dipakai oleh PT. XYZ adalah sistem make to order, yaitu sistem produksi yang dilakukan berdasarkan ada dan banyaknya pesanan yang masuk dari customer. Selain itu ada beberapa jenis produk lensa unggulan yang diproduksi secara masal atau make to stock.

PT. XYZ telah berkomitmen dalam membangun usaha berdasarkan pada peningkatan mutu dan keahlian sumber daya manusia yang berkesinambungan. Hal tersebut dibuktikan dengan berbagai sertifikasi dibidang kualitas yang telah diraih oleh PT. XYZ, salah satunya 
sertifikasi dalam ISO 9001 tahun 2017, mengenai manajemen mutu. Namun meskipun begitu dalam proses produksinya tidak lepas dari adanya cacat produk. Karena PT. XYZ secara umum memproduksi dua tipe lensa yaitu lensa $x$ atau lensa untuk kacamata yang dibagi menjadi dua tipe lainnya yaitu ada $\mathrm{x} 1$, dan $\mathrm{x} 2$. Sedangkan tipe y memiliki tiga jenis lensa berbeda yaitu y1,y2 dan y3. Pada periode 19 Desember 2020, tercatat terdapat 9 jenis cacat produk lensa type $\mathrm{x}$.

Cacat atau defect adalah masalah yang dapat menurunkan hasil produk dan kepuasan serta kepercayaan pelanggan terhadap hasilnya. Selain itu dapat menambah biaya semakin tinggi (Handoko, 1984). Maka di dalam proses produksi juga harus memperhatikan kualitas agar kecacatan produk bisa diminimalisir. Hal ini dapat mengurangi pemborosan dari segi material ataupun biaya produksi lainnya (Purnomo, 2004). Maka biaya produk/unitnya dapat ditekan dan harga produk menjadi lebih kecil. Karena kualitas menjadi salah satu alat perusahaan dalam menghadapi kompetitor (Hakim, 2006; Wisnu, 2013). Selain itu diharapkan mampu menghasilkan produk yang berkualitas dengan harga yang terjangkau. Sehingga harus dilakukan pengendalian kualitas karena penerapan tersebut membuat konsumen yakin (Ariani, 2004). Bahwa kepuasan konsumen merupakan salah satu hal yang diperhatikan oleh perusahaan. Selanjutnya itu jika kepuasan konsumen tercapai maka loyalitas konsumen juga akan meningkat (Besterfield, 1998).

Peningkatan kinerja (kualitas) dapat dicapai dengan menggunakan proses improvement, yaitu aktivitas perusahaan untuk melakukan peningkatan proses yang dapat meningkatkan nilai tambah. Hal ini dikarenakan dengan melakukan proses improvement, diharapkan perusahaan dapat memenuhi keinginan pelanggan (Gasperz, 1998). Sedangkan perusahaan dapat dikatakan berkualitas jika perusahaan tersebut mempunyai sistem produksi yang baik dengan proses yang terkendali (Feingenbaum, 1992). Melalui pengendalian kualitas (quality control) diharapkan bahwa perusahaan dapat meningkatkan efektifitas pengendalian dalam mencegah terjadinya produk cacat (defect prevention) (Montgomery, 2009). Sehingga dapat menekan terjadinya pemborosan dari segi material atau tenaga kerja yang akhirnya dapat meningkatkan produktifitas. Salah satu metode pengendalian kualiatas adalah metode lean six sigma. Maka dari itu penelitian ini bertujuan menganalisis strategi guna mengurangi tingkat kecacatan pada produk lensa tipe $\mathrm{x}$ di $\mathrm{PT}$. XYZ dengan menggunakan metode lean six sigma dengan pendekatan konsep DMAIC.

DMAIC merupakan suatu metode dalam pengukuran nilai sigma yang terdiri dari define, measure, analysis, improve dan control. Berikut merupakan langkah-langkah metode DMAIC(Gasperz, 1998):

1. Define merupakan langkah awal dalam peningkatan kualitas dimulai dari masalah yang diidentifikasi.
2. Measure merupakan aktivitas pengukuran proses sebelumnya (pengukuran dasar), yang bertujuan untuk mengevaluasi berdasarkan goals yang telah ada. Pengukuran tingkat kecacatan sampai tingkat sigmanya.

3. Analyze merupakan tahap yang dilakukan identifikasi akar penyebab masalah dengan berdasarkan analisa data. Dapat menggunakan tools diagram pareto dan fishbone.

4. Improve merupakan tahap penyusunan rekomendasi tindakan secara umum dalam upaya menekan tingkat kecacatan produk.

5. Control merupakan tahap terakhir yang dilakukan dalam peningkatan kualitas menggunakan DMAIC. Langkah terakhir ini bertujuan untuk melakukan control dalam setiap kegiatan. Sehingga memeperoleh hasil yang baik dan dapat mengurangi waktu, masalahdan biaya yang tidak dibutuhkan

Penelitian yang dilakukan oleh Erni Krisnaningsih dan Fadli Hadi: Berdasarkan hasil dari identifikasi sumber terjadinya dari cacat yang terjadi dikarenakan faktor manusia, metode, material dan tools. Dari perhitungan tingkat sigma dan DPMO didapatkan hasil rata-rata levelsigma yaitu 3,92 dengan nilai DPMO 13166,43. Berdasarkan Pareto Diagram, perbaikan difokuskan pada 3 jenis cacat yang terjadi dengan persentase masalah yang harus dituntaskan $80 \%$ sesuai hukum pareto yaitu Sagging dengan persentase $(38,16 \%)$, Orange Peel dengan persentase $(25,65 \%)$ dan Low DFT dengan persentase $(19,06 \%)$. Ketiga cacat tersebut di analisis menggunakan FishboneDiagram untuk menggambarkan penyebab terjadinya cacat. Pada tahap Improve (perbaikan) dilakukan usulan perbaikan dengan metode $5 \mathrm{~W}+1 \mathrm{H}$ sebagai metode untuk pertimbangan perusahaan dalam menerapkan kualitas yang lebih baik dengan dibantu alat statistik untuk mempermudah dalam tahap pengontrolan. Diusahakan perusahaan dapat melakukan penerapan Six Sigma dengan tahap DMAIC (Define, Measure, Analyze, Improve dan Control) kedepannya untuk meningkatkan kualitas dengan harapan yaitu tidak terjadinya cacat atau zero defect yang bermanfaat bagi kondisi ideal perusahaan(Krisnaningsih \& Hadi, 2020).

Penelitian yang dilakukan olehSri Murni Fitria dan Novita: Dalam penelitian ini diketahui bahwa perusahaan yang menjadi objek penelitian tersebut sangat tidak kompetitif karena berada pada level sigma 2.7 dengan nilai DPMO sebesar 106.416,66 (Fitria \& Novita, 2020). Hal ini menunjukkan bahwa dalam proses produksi yang dilakukan masih banyak produk yang tidak sesuai dengan keinginan konsumen. Ada beberapa usulan perbaikan serta pengendalian yang dapat dilakukan yaitu dengan melakukan pengendalian hasil (result control), pengendalian tindakan (action control), pengendalian personel (personel control) dan pengendalian budaya (culture control) (Fitria \& Novita, 2020).

Penelitian yang dilakukan oleh Asep Ridwan, Faula Arina dan Ardi Permana: Tingkat kemampuan sigma yang didapat dalam proses produksi dunnage di 
PT. XYZ sebesar 3,22 dengan nilai DPMO 46231,89 dalam kategori baik untuk rata-rata Industri Indonesia. Selanjutnya dilakukan analisis untuk mengidentifikasi penyebab terjadinya defect dengan fishbone diagram. Usulan perbaikan menggunakan metode $5 \mathrm{~W}+1 \mathrm{H}$, pendekatan $5 \mathrm{~S}$, dan pembuatan tanda bantu dan tabel form dalam pendekatan 5S. Dengan rancangan process activity mapping (PAM) dan value stream mapping, efisiensi proses produksi dunnage bisa meningkat dari 96,85\% menjadi 97,75\%(Ridwan, Arina, \& Permana, 2020).

Penelitian yang dilakukan oleh Somadi: Berdasarkan hasil analisis yang dilakukan maka dapat disimpulkan bahwa jenis keterlambatan yang sering terjadi yakni keterlambatan pengiriman barang. Keterlambatan pengiriman barang disebabkan oleh over pekerjaan yang mengakibatkan penundaan rencana stuffing, staf yang kurang fokus mengakibatkan kesalahan dalam menginformasikan shipping instruction kepada EMKL, terlambat mendapat informasi stockharian gudang sehingga terlambat booking kapal, tidak menginformasikan ulang kepada EMKL atas ketersediaan trucking yang dipesan sehingga kekurangan armada trucking dan menumpuknya dokumen di ruang kerja (Somadi, 2020).

Penelitian yang dilakukan oleh Agus Purwanto dan kawan-kawan: Based on the result of this study, it is concluded that the application of six sigma has a significant effect on the performance of the pharmaceutical industry. The application of six sigma through the DMIC steps, namely determine, measure, improve and control will encourage increased performance of the pharmacy industry (Purwanto, et al., 2020).

Penelitian yang dilakukan oleh Faris Ghiyats, Fadila Marga Sty dan Dewi Riniarti: Rata-rata pencapaian persentase defect tiap bulan sebesar 0,07\% belum mampu mencapai target yang ditentukan perusahaan sebesar $0,03 \%$. Tingkat sigma rata-rata per bulan $(5,04)$ dikategorikan ke dalam tingkatan kualitas rata-rata industri USA. Nilai kapabilitas $(\mathrm{Cp})=1,67$ artinya sangat baik sedangkan indeks kapabilitas (Cpk) $=1,198$ artinya kemampuan proses berkaitan CTQ tersebut perusahaan telah cukup mampu dan perlu upaya yang giat untuk peningkatan kualitas menuju target yang diinginkan. Faktor-faktor yang menyebabkan terjadinya penyimpangan pada produksi sebab-akibat adalah mesin dengan nilai Risk Priority Number (RPN 105) (Ghiyats, Sty, \& Riniarti, 2020).

Penelitian yang dilakukan oleh Selly Apriani Lestari, Chriswardani Suryawati dan J. Sugiarto: Ratarata lama waktu pelayanan yang diterima oleh pasien dari saat pasien datang sampai pasien menerima obat adalah 199.4 menit untuk pasien umum dan 408.4 menit untuk pasien BPJS. Selama proses pelayanan poli klinik di RSUD Dr. Soeratno Gemolong waste yang terjadi adalah waiting, overprocessing, overproduction, inventory, motion, transportation dan human potential. Penelitian ini membuktikan penerapan prinsip, alat, dan metode lean dapat mengidentifikasi dan mengeliminasi waste di pelayanan rawat jalan, mempersingkat prosedur di semua unit pelayanan rawat jalan sehingga menurunkan waktu tunggu, meningkatkan kualitas pelayanan dan meningkatkan kepuasan kerja petugas dan kepuasan pasien (Lestari, Suryawati, \& Sugiarto, 2020).

Penelitian yang dilakukan oleh Poppy Rahayu dan Merita Bernik: Berdasarkan perhitungan di peroleh nilai defect per million opportunity(DPMO) sebesar 3603,64 dan nilai sigma sebesar 4,18.Pada tahap define digunakan diagram pareto untuk mengetahui jumlah dan jeniskecacatan, tahap measure menggunakan control P-chart untuk mengetahui kecacatanproduk masih dalam batas yang diisyaratkan, tahap analyze menggunakan fishbonediagram untuk mengetahui faktor penyebab terjadi kecacatan, penggunaan process decision program chart untuk pemetaan usulan perbaikan pada tahapimprove, tahapcontrol menghitung nilai sigma produk dan menyusun flowchart proses produksi (Rahayu \& Bernik, 2020).

Penelitian yang dilakukan olehReni Dwi Astuti dan Lathifurahman: Penyebab kecacatan produk dianalisis dengan fish-bonediagram. Lebih lanjut, Failure Mode and Effect Analysis (FMEA) digunakan untuk merancang ususlan perbaikan. hasil penelitian ini menunjukan adanya Pemborosan padatransportation, motion, waiting, overprocessing dan defect. Usulan perbaikan dilakukan dengan penggabungan stasiun penimbangan dan stasiun pemeriksaan. Sehingga memberikan estimasi peningkatan effisiensi dari $39.1 \%$ menjadi 46.69\% (Astuti \& Lathifurahman, 2020).

Penelitian yang dilakukan oleh Khusnun Nabila dan Rochmoeljati:Sehingga diperoleh DPMO rata-rata sebesar 17.531,93 dengan nilai sigma sebesar 3,61.Dari hasil DPMO dan nilai sigma tersebut dapat diketahui ada lima jenis factor yang mempengaruhi kecacatan, yaitu faktor man, milleu, machine, method dan materials. Berdasarkan pemasalahn di setiap factor maka dilakukan continues improvement dengan metode Kaizen Five Mchecklist dan Five Step Plan atau 5S (Seiri, Seiton, Seiso, Seiketsu dan Shitsuke) yang digunakan rekomendasi perbaikan untuk menyelesaikan kelima faktor penyebab defect tersebut (Nabila \& Rochmoeljati, 2020).

Tahapan measure pada penelitian ini dilakukan dengan langkah: (1) menghitung defect/unit (DPU), (2) menghitung total opportunitiest (TOP), (3) menghitung defect/opportunitiest (DPO), (4) menghitung defect/million opportunitiest (DPMO) dan (5) menghitung tingkat sigma. Sehingga dapat diketahui proporsi tingkat kecacatan secara menyeluruh, mulai dari tingkat cacat/unit, total cacat sampai dengan tingkat sigma. Tahap improvment dirumuskan menggunakan metode $5 \mathrm{~W}+1 \mathrm{H}$. Sehingga usulan perbaikan dapat difokuskan pada sebab kecacatan tersebut muncul. Maka dapat dikaji bentuk pencegahan agar penyebab cacat tersebut tidak terjadi kembali, atau setidaknya dapat dikendalikan. 


\section{Bahan dan Metode}

Penelitian ini diawali dengan melakukan identifikasi masalah yang terjadi di PT. XYZ. Lalu setelah itu dilanjutkan dengan studi literatur dari beberapa jurnal penelitian terdahulu. Hal tersebut berguna untuk mencari referensi penelitian serta pembuatan literature review. Selanjutnya dilakukan pengambilan data, dengan cara wawancara langsung kepada pihak dari perusahaan mengenai temuan masalah yang terjadi. Lalu dilanjutkan dengan pengolahan data dengan menggunakan metode six sigma (DMAIC). Tahap define dilakukan dengan mengidentifikasi masalah cacat produk lensa tipe $\mathrm{x}$. Lalu tahap measure dilakukan dengan perhitungan dan analisis produk cacat lensa tipe $\mathrm{x}$. Tahap analyze dilakukan dengan membuat diagram pareto yang digunakan untuk mengetahui tingkat atau persentase cacat tertinggi dari produk lensa tipe x. Selain itu untuk mengetahui sebab akibat terjadinya kecacatan produk dilakukan analisa menggunakan fishbone diagram. Tahap improve merupakan usulan perbaikan untuk meminimalisir cacat produk dengan harapan dapat terwujudnya zero defect dengan menggunakan tools $5 \mathrm{~W}+1 \mathrm{H}$. Tahap control adalah pengecekan secara terus-menerus agar tujuan kualitas tersebut dapat tercapai. Alur penelitian yang dilakukan seperti pada Gambar 1. di bawah ini:

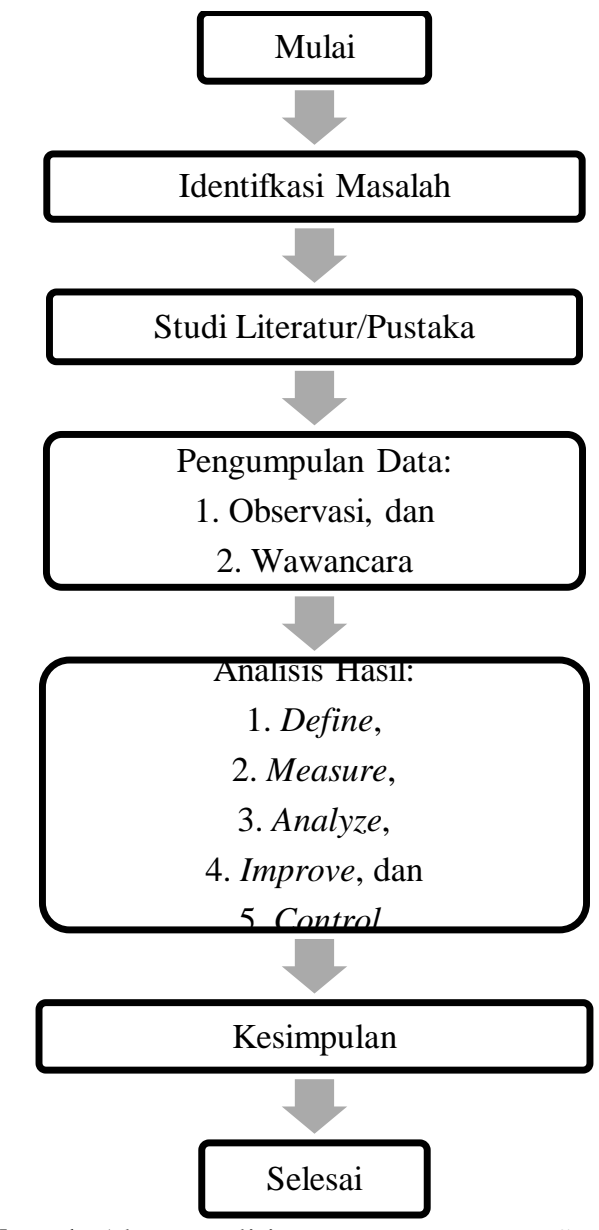

Gambar 1. Alur Penelitian Penerapan Lean Six Sigma dengan Konsep DMAIC

\section{Hasil dan Pembahasan}

Proses produksi lensa x di PT. XYZ dapat dilihat dalam bagan di bawah ini:

1. Pembuatan IR merupakan tahap atau bagian alur produksi yang memproduksi bagian cairan resin yang digunakan sebagai bahan utama dari lensa. Tahap ini sendiri terdiri dari beberapa proses atau tahapan tersendiri sampai menjadi resin yang siap dimasukan pada cetakan lensanya ( mold).

2. Pembuatan gasket merupakan sebuah pengikat antara Mold (cetakan lensa) yang terbuat dari berbagai macam bahan plastik yang elastis. Gasket sendiri sangat berpengaruh dalam menentukan kualitas lensa yang dihasilkan baik atau tidak. Karenanya gasket haruslah selalu lentur dan mampu merekatkan kedua mold yang mencetak cairan resin agar menjadi lensa. Maka dari itu, jika gasket tersebut mengalami masalah atau bocor maka bisa dipastikan lensa yang dihasilkan akan reject.

3. Pembuatan mold merupakan media yang digunakan untuk mencetak lensa, bisa dikatakan mold merupakan cetakannya lensa. Sehingga posisi mold tentu sangat berperan krusial dalam proses pembuatan lensa ini. Mold yang digunakan merupakan sebuah mold yang sengaja di order dari supplier untuk selanjutnya dimodifikasi sesuai dengan kebutuhan dan spesifikasi mold yang digunakan dalam produksi lensa di PT. XYZ. Selanjutnya proses perakitan mold menggunakan gasket.

4. Proses filling, proses curing, lenspick dan pemeriksaan yaitu proses memasukan cairan resin (IR) yang sudah siap kedalam mold yang sudah dipasang karet perekat (gasket). Lalu setelah proses filling, masuk ketahap perebusan lensa mold yang sudah terisi resin tersebut, dan prosesnya dinamakan curing. Setelah itu proses curing selesai maka masuk ke tahap lenspick yaitu proses membuka cetakan (mold) untuk diambil lensa yang sudah jadi. Baru setelahnya masuk ketahap QC atau pemeriksaaan. Pembuatan cairan lapisan anti-radiasi, lalu pelapisan cairan ar pada lensa jadi.

Pengolahan data akan dilakukan menggunakan metode lean six sigmadengan pendekatan DMAIC sebagai berikut:

1. Define

Tabel 1. Jenis Cacat Produk Lensa Tipe $X$

\begin{tabular}{lcc}
\hline Jenis Cacat & $\begin{array}{c}\text { Jumlah Cacat } \\
\text { (Unit) }\end{array}$ & $\begin{array}{c}\text { Jumlah } \\
\text { Produksi }\end{array}$ \\
\hline Bubble & 2344 & \\
Edge Problem & 24 & \\
Crack & 32 & \\
Rellease & 66 & 231728 \\
Lin & 35 & \\
Scratches & 184 & \\
Mold Derty & 487 & \\
Prishm & 8 & \\
Thickness Out & 1358 & \\
\hline Jumlah & 4538 & \\
\hline
\end{tabular}


Jurnal Pendidikan dan Aplikasi Industri (UNISTEK)

Vol. 8 No.1 Februari 2021

p- ISSN : 0126 - 4036

e- ISSN : $2716-0416$

Berdasarkan data yang telah dikumpulkan dan di analisis. Selama kurun waktu Desember 2019, terdapat 9 jenis defect pada produksi lensa tipe $\mathrm{x}$.

Pada Tabel 1 menyatakan ada 9 jenis cacat yang terjadi pada saat produksi lensa tipe $\mathrm{x}$. Selanjutnya dilakukan perhitungan persentase setiap jenis cacatnya, seperti contoh perhitungan jenis cacat bubble di bawah ini: $\frac{\text { Jumlah Cacat Bubble(Unit) }}{\text { Jumlah Cacat }}=\frac{2344}{4538} \times 100 \%=51,65$

Selanjutnya hitung persentase jenis cacat lainnya sampai diketahui setiap nilai persentasenya, dan akumulasi persentase setiap jenis cacat secara lengkap.Secara lengkap dapat dilihat dalam gambar 2 yang menunjukan frekuensi masing-masing cacat terhadap total cacat. Seperti pada Gambar 2. di bawah ini:

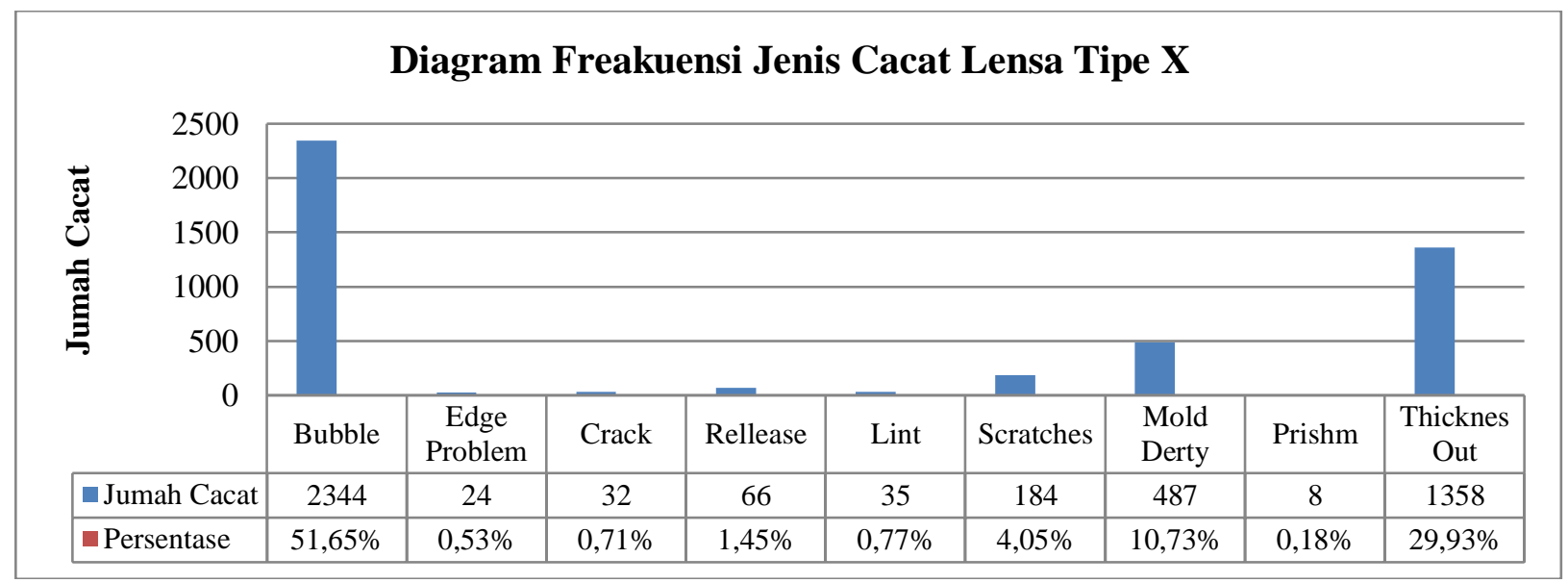

Gambar 2. Diagram Frekuensi Jenis Cacat Lensa Tipe X

Terlihat dalam Gambar 2. di atas berdasarkan hasil perhitungan persentase produk cacat dengan jumlah produksi dari masing-masing defect produk lensa x. Memiliki persentase rata-rata pada jenis bubble $51,65 \%$, edge problem $0,53 \%$, crack $0,71 \%$, relllease $1,45 \%$, lint $0,77 \%$, scratches $4,05 \%$, moldderty $10,73 \%$, prishm $0,18 \%$, thicknes out $29,93 \%$.

2. Measure

Proses perhitungan menggunakan metode lean six sigma seperti di bawah ini:

a. Perhitungan Nilai Defect/㡍it (DPU)

$$
\text { DPU }=\frac{\text { Jumlah Produk Cacat (D) }}{\text { Total Produksi }}
$$

Contoh perhitungan DPU dari jenis cacat bubble seperti di bawah ini:

$$
\text { DPU Bubble }=\frac{2344}{231728}=0,010115
$$

Tabel 2. Hasil Perhitungan Defect/Unit Lensa Tipe $\mathrm{X}$

\begin{tabular}{clc}
\hline No & Jenis Cacat & DPU \\
\hline 1 & Bubble & 0,010115 \\
2 & Edge Problem & 0,000104 \\
3 & Crack & 0,000138 \\
4 & Rellease & 0,000285 \\
5 & Lin & 0,000151 \\
6 & Scratches & 0,000794 \\
7 & Mold Derty & 0,002102 \\
8 & Prishm & 0,000035 \\
9 & Thickness Out & 0,005860 \\
\hline
\end{tabular}

Lalu hitung DPU jenis cacat lain seperti contoh DPU bubble di atas. Akumulasi perhitungan nilai defect/unit (DPU) dapat dilihat dalam Tabel 2.

b. Menentukan Total Opportunitiest (TOP) TOP = Total Produk x Jumlah Cacat (CTQ) (2)

Opportunitiest adalah banyaknyc kesempatan yang dapat mengakibatkan cacat berdasarkan proses produksi lensa type $\mathrm{x}$ terdapa 9 langkah proses produksi, termasuk perakitar diantaranya: Pembuatan Cairan Resin, Proses pembuatan Mold, Proses Pembuatan Gasket, Proses Perakitan Mold menggunakan Gasket, Proses Filling, Proses Curring, Proses Lenspick, Proses Pembuatan cairan Ar (Anti Radiasi), penyemprotan cairan Anti Radiasi pada Lensa jadi Sehingga rumus TOP menjadi:

TOP $=$ Total Produk $\times$ Opportunitiest $\mathrm{TOP}=231728 \times 9=2085552$

c. Perhitungan Nilai Defect/Opportunitiest (DPO)

$$
\text { DPO }=\frac{\text { Total Produk Cacat (D) }}{\text { TOP }}
$$

Contoh perhitungan jenis defectbubble seperti di bawah ini:

$$
\text { DPO }=\frac{2344}{2085552}=0,001124
$$

Selanjutnya hitung DPO semua jenis defect seperti perhitungan di atas, dan akumulasi perhitungan semua jenis defect dapat dilihat dalam Tabel 3. di bawah ini: 
Jurnal Pendidikan dan Aplikasi Industri (UNISTEK)

Vol. 8 No.1 Februari 2021

p- ISSN : 0126 - 4036

e- ISSN : $2716-0416$

Tabel 3. Hasil Perhitungan Defect/Opportunitiest Lensa Tipe $\mathrm{X}$

\begin{tabular}{clc}
\hline No & Jenis Cacat & DPO \\
\hline 1 & Bubble & 0,001124 \\
2 & Edge Problem & 0,000012 \\
3 & Crack & 0,000015 \\
4 & Rellease & 0,000032 \\
5 & Lin & 0,000017 \\
6 & Scratches & 0,000088 \\
7 & Mold Derty & 0,000234 \\
8 & Prishm & 0,000004 \\
9 & Thickness Out & 0,00651 \\
\hline
\end{tabular}

d. Perhitungan Defect/Million Opportunitiest (DPMO)

$$
\text { DPMO = DPO } \times 1.000 .000
$$

Contoh perhitungan DPMO defect jenis bubble seperti di bawah ini:

$$
\mathrm{DPMO}=0,001124 \times 1.000 .000=1124
$$

Selanjutnya hitung DPMO semua jenis defect seperti perhitungan di atas, dan akumulasi perhitungan semua jenis defect dapat dilihat dalam Tabel 4. di bawah ini:

Tabel 4. Hasil Perhitungan Defect/Million Opportunities Lensa Tipe X

\begin{tabular}{clc}
\hline No & Jenis Cacat & DPMO \\
\hline 1 & Bubble & 1124 \\
2 & Edge Problem & 12 \\
3 & Crack & 15 \\
4 & Rellease & 32 \\
5 & Lin & 17 \\
6 & Scratches & 88 \\
7 & Mold Derty & 234 \\
8 & Prishm & 4 \\
9 & Thickness Out & 651 \\
\hline
\end{tabular}

e. Perhitungan Tingkat Sigma

$$
\text { T.Sigma }=N \operatorname{orm} \operatorname{sinv}\left(1-\frac{\mathrm{DPMO}}{1.000 .000}\right)+1,5
$$

Contoh perhitungan tingkat sigmadefect jenis bubble seperti di bawah ini:

$$
\begin{gathered}
\text { T. Sigma }=\text { Normsinv }\left(1-\frac{1124}{1.000 .000}\right)+1,5 \\
\text { T. Sigma Bubble }=4,555368
\end{gathered}
$$

Selanjutnya hitung tingkat sigma semua jenis defect seperti perhitungan di atas, dan akumulasi perhitungan semua jenis defect dapat dilihat dalam Tabel 5. di bawah ini:

Tabel 5. Hasil Perhitungan Tingkat Sigma Lensa Tipe X

\begin{tabular}{clc}
\hline No & Jenis Cacat & Tingkat Sigma \\
\hline 1 & Bubble & 4,555368 \\
2 & Edge Problem & 5,733429 \\
3 & Crack & 5,668305 \\
4 & Rellease & 5,500186 \\
5 & Lin & 5,647829 \\
6 & Scratches & 5,250543 \\
7 & Mold Derty & 4,998991 \\
8 & Prishm & 5,974143 \\
9 & Thickness Out & 4,715474 \\
\hline
\end{tabular}

Berdasarkan hasil perhitungan di atas diketahui bahwa perusahaan sudah cukup baik dalam penanganan tingkat kecacatan. Hal ini berdasarkan nilai sigma yang mendekati 6 (dalam artian hampir zero defect pada jenis cacatnya). Akan tetapi dapat terlihat dalam Tabel 5. di atas bahwa kecacatan produk lensa tipe $\mathrm{x}$ masih terjadi. Maka perbaikan serta pengendalian kulitas harus selalu dilakukan agar harapan perusahaan mengenai zero defect bisa terjadi.

3. Analyze

Analisis dalam metode lean six sigma menggunakan diagram pareto dan fishbone. Untuk diagram pareto Seperti pada Gambar 3. di bawah ini:

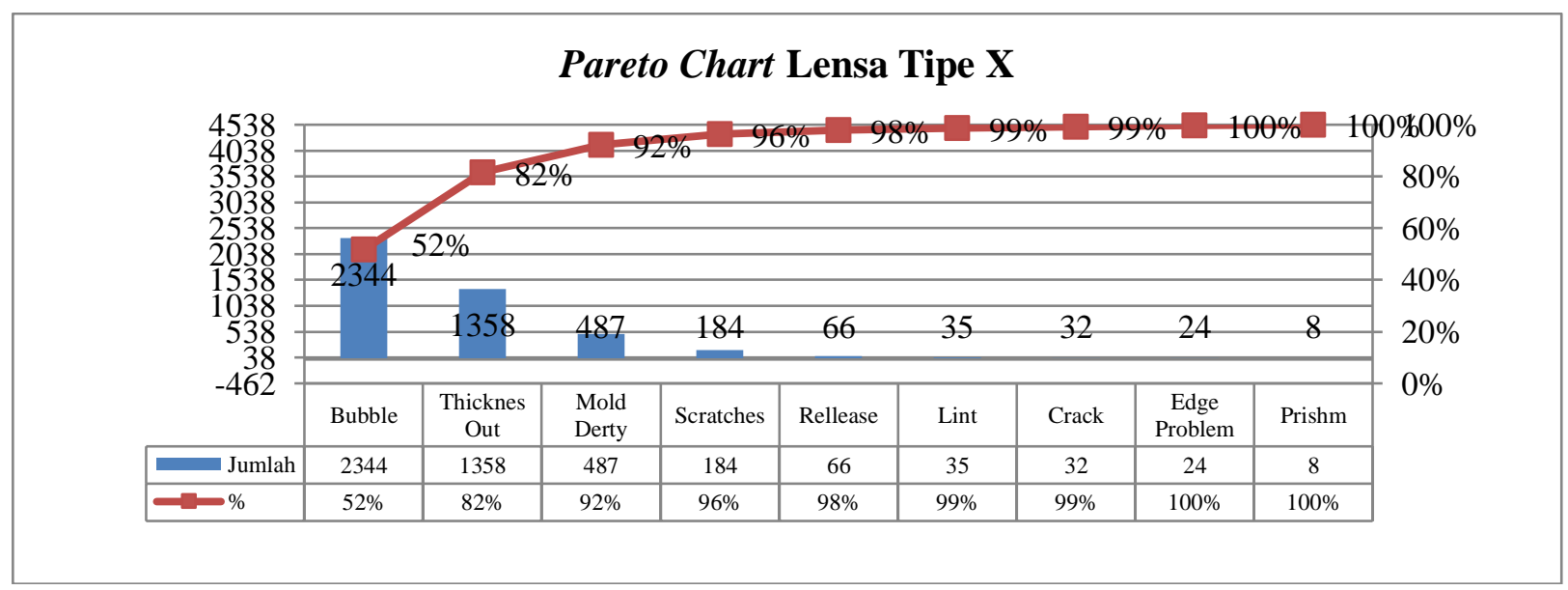

Gambar 3.Pareto Chart Lensa Tipe X 
Jurnal Pendidikan dan Aplikasi Industri (UNISTEK)

Vol. 8 No.1 Februari 2021

p- ISSN : 0126 - 4036

e- ISSN : $2716-0416$

Berdasarkan diagram pareto seperti Gambar 3. di atas, terlihat bahwa ada 3 jenis defect dengan nilai cacat paling tinggi (dominan). Yaitu jenis defect bubble dengan persentase cacat 52\%, thicknes out $30 \%$ dan mold derty 10\%. Maka berdasarkan diagram pareto langkah perbaikan akan diprioritaskan pada 3 jenis cacat yang paling dominan tersebut. Selanjutnya dilakukan analisis sebab akibat dari kemungkinan terjadinya defect pada ketiga jenis cacat prioritas tersebut dengan menggunakan diagram fishbone. Seperti pada Gambar 4. 5. dan 6. di bawah ini:

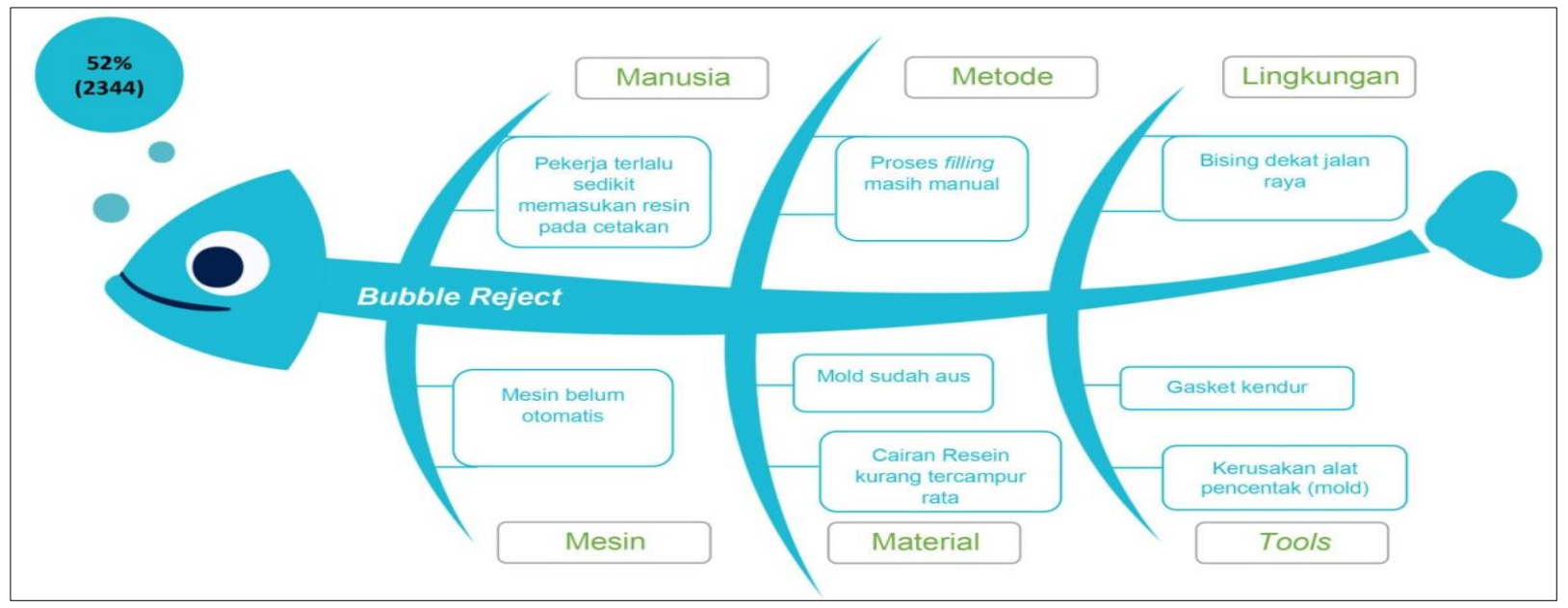

Gambar 4. Diagram Fishbone Bubble Defect

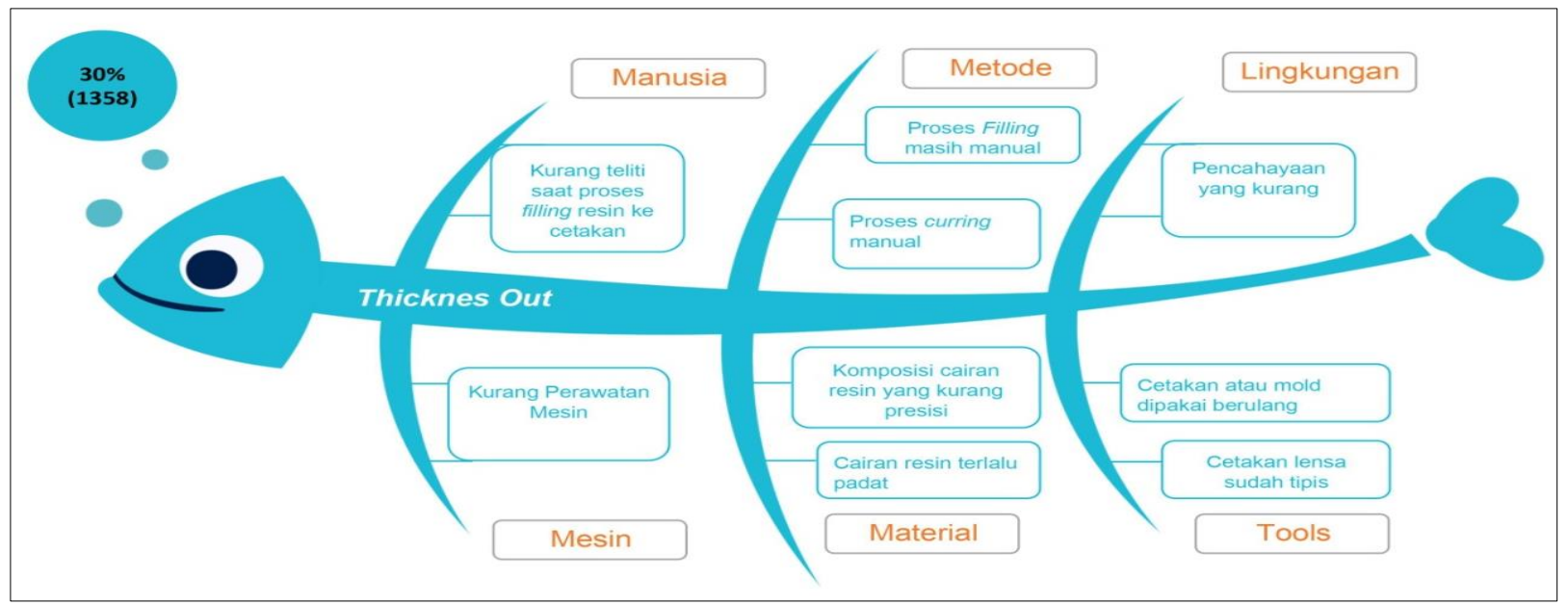

Gambar 5.Diagram Fishbone Thicknes Out Defect

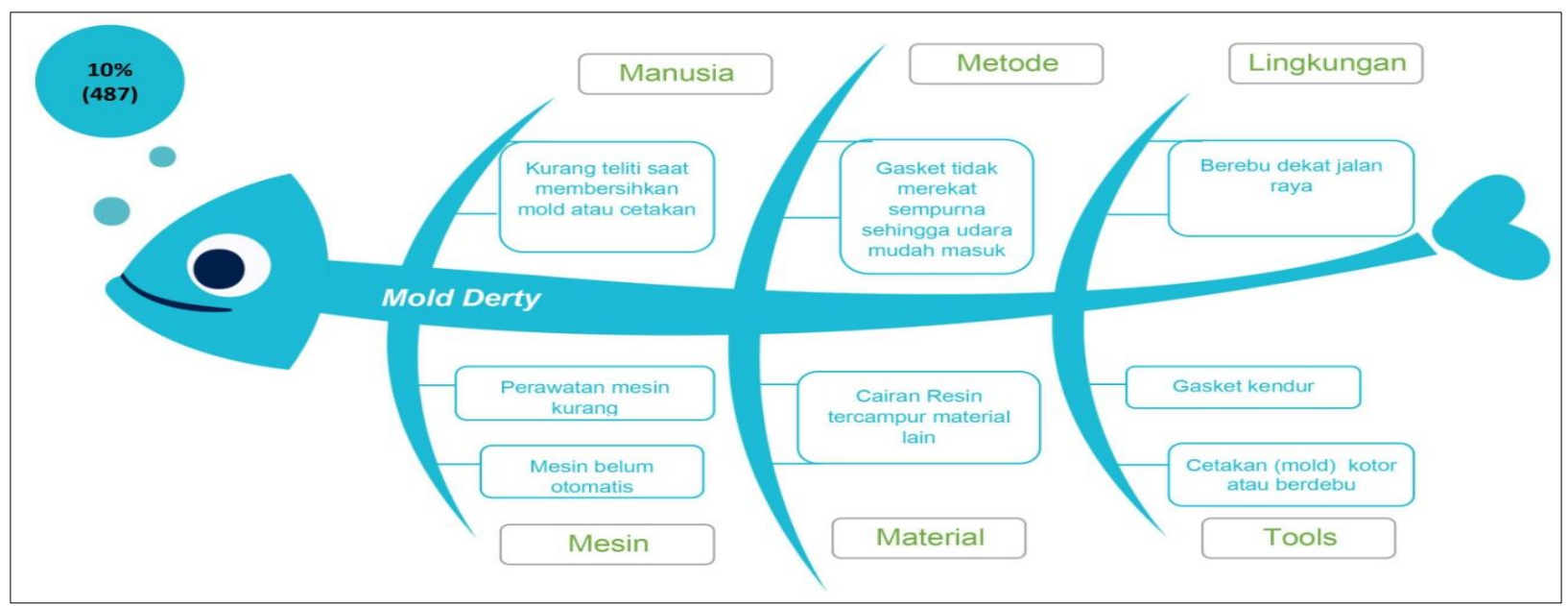

Gambar 6. Diagram Fishbone Mold Derty Defect

Jurnal Pendidikan dan Aplikasi Industri, Volume 8, Nomor 12021 | 24 
Jurnal Pendidikan dan Aplikasi Industri (UNISTEK)

Vol. 8 No.1 Februari 2021

p- ISSN : 0126 - 4036

e- ISSN : $2716-0416$

4. Improve

Pada tahap perbaikan dilakukan analisis perbaikan dengan menggunakan metode $5 \mathrm{~W}+1 \mathrm{H}$, seperti Tabel 6. di bawah ini:

Tabel 6. $5 \mathrm{~W}+1 \mathrm{H}$ Lensa Tipe $\mathrm{X}$

\begin{tabular}{|c|c|c|c|c|c|c|}
\hline \multirow{2}{*}{$\begin{array}{c}\text { Waktu } \\
\text { Terjadi } \\
\text { (When) }\end{array}$} & \multirow{2}{*}{$\begin{array}{l}\text { Defect } \\
\text { Terjadi } \\
\text { (What) }\end{array}$} & \multirow{2}{*}{$\begin{array}{c}\text { Terjadinya } \\
\text { Defect } \\
(\text { Where })\end{array}$} & \multicolumn{2}{|c|}{ Penyebab (Why) } & \multirow{2}{*}{$\begin{array}{l}\text { Penanggung } \\
\text { Jawab }(\text { Who })\end{array}$} & \multirow{2}{*}{$\begin{array}{c}\text { Perbaikan } \\
(\text { How })\end{array}$} \\
\hline & & & $\begin{array}{c}\text { Faktor } \\
\text { Penyebab }\end{array}$ & Penyebab & & \\
\hline \multirow[t]{6}{*}{$\begin{array}{c}\text { Saat } \\
\text { berlangsung } \\
\text { proses } \\
\text { produksi }\end{array}$} & Bubble & $\begin{array}{c}\text { Terjadi saat } \\
\text { proses } \\
\text { filling }\end{array}$ & Manusia & $\begin{array}{l}\text { Pekerja selalu } \\
\text { sedikit } \\
\text { memasukan } \\
\text { resin pada saat } \\
\text { proses filling } \\
\text { pada cetakan }\end{array}$ & $\begin{array}{l}\text { Pekerja bagian } \\
\text { proses filling } \\
\text { dan QC }\end{array}$ & $\begin{array}{l}\text { Sebaiknya } \\
\text { pekerja } \\
\text { memastikan } \\
\text { setiap takaran } \\
\text { proses filling } \\
\text { sesuai SOP } \\
\end{array}$ \\
\hline & & & Mesin & $\begin{array}{l}\text { Mesin proses } \\
\text { filling masih } \\
\text { beban } \\
\text { otomatis }\end{array}$ & $\begin{array}{c}\text { Pihak } \\
\text { manajemen }\end{array}$ & $\begin{array}{c}\text { Sebaiknya pihak } \\
\text { manajemen } \\
\text { membeli } \\
\text { (menambahkan) } \\
\text { mesin yang } \\
\text { memiliki sensor, } \\
\text { untuk } \\
\text { memastikan } \\
\text { cetakan (mold) } \\
\text { berjalan dengan } \\
\text { baik }\end{array}$ \\
\hline & & & Metode & $\begin{array}{l}\text { Proses filling } \\
\text { masih manual }\end{array}$ & $\begin{array}{c}\text { Pihak } \\
\text { manajemen dan } \\
\text { QA }\end{array}$ & $\begin{array}{c}\text { Sebaiknya pihak } \\
\text { manajemen dan } \\
\text { QA } \\
\text { mengimprove } \\
\text { metode proses } \\
\text { filling, misal } \\
\text { dengan } \\
\text { kombinasi alat } \\
\text { otomatis }\end{array}$ \\
\hline & & & Material & $\begin{array}{l}\text { Mold sudah } \\
\text { kering dan } \\
\text { cairan resin } \\
\text { kurang } \\
\text { tercampur rata }\end{array}$ & $\begin{array}{c}\text { Pihak } \\
\text { departemen } \\
\text { mold shop dan } \\
\text { purchase serta } \\
\text { pekerja bagian } \\
\text { laboratorium } \\
\text { resin, QA }\end{array}$ & $\begin{array}{c}\text { Sebaiknya mold } \\
\text { digunakan untuk } \\
\text { sekali pakai, dan } \\
\text { ada pengecekan } \\
\text { berkala di } \\
\text { laboratorium } \\
\text { saat proses } \\
\text { pembuatan } \\
\text { cairan resin } \\
\end{array}$ \\
\hline & & & Lingkungan & $\begin{array}{l}\text { Bising dekat } \\
\text { dengan jalan } \\
\text { raya }\end{array}$ & Departemen K3 & $\begin{array}{c}\text { Menambahkan } \\
\text { atribut K3, yang } \\
\text { mampu } \\
\text { meredam } \\
\text { kebisingan, } \\
\text { serta memastikn } \\
\text { pekerja } \\
\text { mematuhinya }\end{array}$ \\
\hline & & & Tools & $\begin{array}{c}\text { Gasket } \\
\text { kendur, dan } \\
\text { kerusakan alat } \\
\text { pencetak } \\
(\text { mold })\end{array}$ & $\begin{array}{c}\text { Maintenance, } \\
\text { QC }\end{array}$ & $\begin{array}{c}\text { Gasket } \\
\text { sebaiknya } \\
\text { digunakan untuk } \\
\text { sekali pakai, } \\
\text { begitu dengan } \\
\text { mold dan ada }\end{array}$ \\
\hline
\end{tabular}


pengecekan QC

sebelum

melakukan

produksi.

\begin{tabular}{|c|c|c|c|c|c|c|}
\hline $\begin{array}{l}\text { Waktu } \\
\text { Terjadi } \\
\text { (When) }\end{array}$ & $\begin{array}{l}\text { Defect } \\
\text { Terjadi } \\
\text { (What) }\end{array}$ & $\begin{array}{l}\text { Terjadinya } \\
\text { Defect } \\
\text { (Where) }\end{array}$ & $\begin{array}{c}\text { Penyebab } \\
(\text { Why })\end{array}$ & $\begin{array}{l}\text { Penanggung } \\
\text { Jawab (Who) }\end{array}$ & $\begin{array}{l}\text { Perbaikan } \\
\quad(\text { How })\end{array}$ & $\begin{array}{c}\text { Waktu Terjadi } \\
\text { (When) }\end{array}$ \\
\hline \multirow[t]{6}{*}{$\begin{array}{c}\text { Saat } \\
\text { berlangsung } \\
\text { proses } \\
\text { produksi }\end{array}$} & \multirow[t]{6}{*}{$\begin{array}{c}\text { Thickes } \\
\text { Out }\end{array}$} & \multirow[t]{6}{*}{$\begin{array}{l}\text { Terjadi } \\
\text { pada proses } \\
\text { pemilihan } \\
\text { mold, } \\
\text { curing dan } \\
\text { filing }\end{array}$} & Manusia & $\begin{array}{l}\text { Kurang teliti } \\
\text { saat proses } \\
\text { filling resin ke } \\
\text { QC }\end{array}$ & $\begin{array}{l}\text { Pekerja bagian } \\
\text { proses filling } \\
\text { dan QC }\end{array}$ & $\begin{array}{c}\text { Sebaiknya } \\
\text { pekerja } \\
\text { memastikan } \\
\text { setiap takaran } \\
\text { proses filling } \\
\text { sesuai SOP dan } \\
\text { QC selalu } \\
\text { melakukan } \\
\text { pengecekan } \\
\text { berkala }\end{array}$ \\
\hline & & & Mesin & $\begin{array}{l}\text { Departemen } \\
\text { Maintenance }\end{array}$ & $\begin{array}{l}\text { Departemen } \\
\text { Maintenance }\end{array}$ & $\begin{array}{c}\text { Sebaiknya } \\
\text { pengecekan } \\
\text { dilakukan dalam } \\
\text { kurun waktu } \\
\text { yang tidak lama } \\
\text { dan lebih baik } \\
\text { secara berkala }\end{array}$ \\
\hline & & & Metode & $\begin{array}{c}\text { Proses filling } \\
\text { masih manual, } \\
\text { dan proses } \\
\text { curring } \\
\text { manual }\end{array}$ & $\begin{array}{l}\text { Manajemen } \\
\text { dan QA }\end{array}$ & $\begin{array}{c}\text { Sebaiknya pihak } \\
\text { manajemen dan } \\
\text { QA } \\
\text { mengimprove } \\
\text { metode proses } \\
\text { filling dan } \\
\text { curring, misal } \\
\text { dengan } \\
\text { kombinasi alat } \\
\text { yang otomatis }\end{array}$ \\
\hline & & & Material & $\begin{array}{l}\text { Komposisi } \\
\text { cairan resin } \\
\text { yang kurang } \\
\text { presisi, dan } \\
\text { cairan resin } \\
\text { terlalu padat } \\
\quad(\text { kental) }\end{array}$ & $\begin{array}{l}\text { Pekerja bagian } \\
\text { proses resin } \\
\text { dan QC }\end{array}$ & $\begin{array}{c}\text { Sebaiknya } \\
\text { pekerja dan QC } \\
\text { memastikan } \\
\text { setiap komposisi } \\
\text { material yang } \\
\text { digunakan } \\
\text { sebelum } \\
\text { melakukan } \\
\text { proses produksi }\end{array}$ \\
\hline & & & Lingkungan & $\begin{array}{l}\text { Pencahayaan } \\
\text { yang kurang }\end{array}$ & Departemen K3 & $\begin{array}{c}\text { Sebaiknya ada } \\
\text { pencahayaan } \\
\text { tanpa } \\
\text { menganggu } \\
\text { kondisi SOP } \\
\text { suhu dan ruang, } \\
\text { mungkin dapat } \\
\text { menambahkan } \\
\text { sensor yang } \\
\text { otomatis } \\
\end{array}$ \\
\hline & & & Tools & $\begin{array}{c}\text { Cetakan yang } \\
\text { dipakai } \\
\text { berulang, dan }\end{array}$ & $\begin{array}{c}\text { Departemen } \\
\text { QC }\end{array}$ & $\begin{array}{c}\text { Mengecek } \\
\text { cetakan sebelum } \\
\text { proses produksi }\end{array}$ \\
\hline
\end{tabular}


Jurnal Pendidikan dan Aplikasi Industri (UNISTEK)

Vol. 8 No.1 Februari 2021

p- ISSN : 0126 - 4036

e- ISSN : $2716-0416$

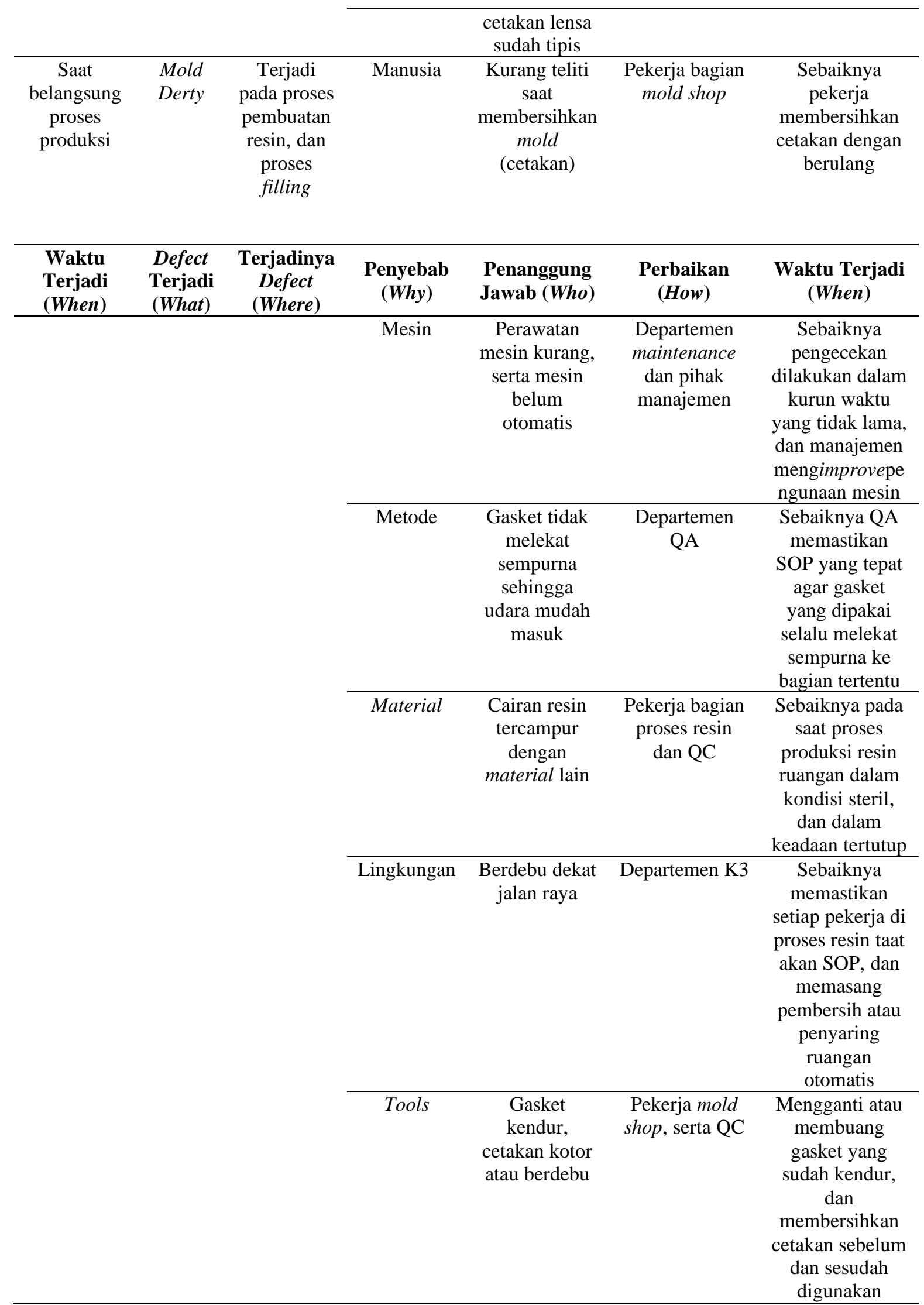

Tahap control dijelaskan dalam bentuk masukan untuk perusahaan seperti yang tertera pada 
tabel $5 \mathrm{~W}+1 \mathrm{H}$. Sehingga setidaknya dapat membantu perusahaan dalam melakukan pengendalian kualitas. Setelah dilakukan perbaikan maka perusahaan masih perlu melakukan pengendalian kualitas secara terus menerus. Seperti melakukan pengecekan perbaikan secara continuous yang meliputi:

a. Melakukan perawatan mesin dan alat pembuatan lensa secara berkala, sebagai bentuk pencegahan produk cacat.

b. Melakukan pencatatan produk cacat setiap harinya apabila ada.

c. Melakukan pengawasan bahan baku pembuatan lensa

Hal tersebut sejalan dengan penelitian (Safrizal \& Muhajir, 2016) yang mana pada tahap control menekankan pada tahap pendokumentasian dari tindakan.

\section{Kesimpulan}

Dari hasil penelitian, diketahui bahwa ada 9 jenis cacat (defect) dari produk lensa tipe $\mathrm{x}$ diantaranya: bubble, mold derty, thicknes out, edge problem, crack, rellease, lint, scratches, dan prishm. Dari hasil perhitungan didapatkan rata-rata level sigma yaitu 5,3 dengan nilai rata-rata DPMO sebesar 242. Berdasarkan diagram pareto, perbaikan diprioritaskan pada 3 (tiga) jenis cacat yang paling dominan. Yaitu jenis defect Bubble dengan persentase cacat 52\%, Thicknes Out $30 \%$ dan Mold Derty 10\%. Kemudian dilakukan analisis sebab akibat menggunakan fishbone, diketahui bahwa faktor manusia, material, tools, mesin, lingkungan dan metode menjadi faktor penyebab terjadinya ketiga jenis cacat.

Langkah perbaikan selanjutnya dapat dilakukan dengan menerapkan rekomendasi pada analisis metode $5 \mathrm{~W}+1 \mathrm{H}$. Hal ini berdasarkan hasil perhitungan di atas diketahui bahwa perusahaan sudah cukup baik dalam penanganan tingkat kecacatan. Dikarenakan nilai sigma yang mendekati 6 (dalam artian hampir zero defect pada jenis kecacatan). Selain itu dalam jenis cacat tertentu tingkat kecacatannya masih cukup tinggi dengan tingkat sigma yang rendah. Maka perbaikan serta pengendalian kulitas harus selalu dilakukan agar harapan perusahaan mengenai zero defect bisa terjadi. Sejalan dengan jurnal (Kabir et al., 2013) yang mengatakan bahwa six sigma is a statistical measurement of only 3.4 defects per million.

\section{Daftar Pustaka}

Ariani, D. W. (2004). Pengendalian Kualitas Statistik. Yogyakarta: Andi Offset.

Astuti, R. D., \& Lathifurahman. (2020). Aplikasi Lean Six-Sigma untuk Mengurangi
Pemborosan di Bagian Packaging Semen. Jurnal Teknik Industri, 44-52.

Besterfield, D. H. (1998). Quality Control. New Jersey: Prentice-Hall Inc.

Feingenbaum, A. V. (1992). Total Quality Control. In K. H., Kendali Mutu Terpadu (pp. 50-62). Jakarta: Erlangga.

Fitria, S. M., \& Novita. (2020). Six Sigm sebagai Strategi Bisnis dalam Upaya Peningkatan Kualitas Produk. Jurnal Akuntansi Terapan Indonesia, 1-14.

Gasperz, V. (1998). Total Quality Management. Jakarta: Gramedia Pustaka Umum.

Ghiyats, F., Sty, F. M., \& Riniarti, D. (2020). Analisis Pengendalian Kualitas dalam Upaya Meminimalisasi Tingkat Kerusakan Gula Rafinasi. Jurnal Agro Industri Perkebunan, 6983.

Hakim, A. N. (2006). Manajemen Industri. Yogyakarta: Andi Offset.

Handoko, T. H. (1984). Dasar-Dasar Manajemen Produksi dan Operasi. Yogyakarta: BPFE.

Kabir, E., Boby, S. M. M. I., \& Lutfi, M. (2013). Productivity Improvement by using Six-Sigma. 3(12), 56-84.

Krisnaningsih, E., \& Hadi, F. (2020). Strategi Mengurangi Produk Cacat pada Pengecatan Boiler Steel Structure dengan Metode Six Sigma di PT. Cigading Habeam Center. Jurnal InTent, 11-24.

Lestari, S. A., Suryawati, C., \& Sugiarto, J. (2020). Analisis Waste dengan Model Lean Hospital pada Pelayanan Poli Rawat Jalan. Jurnal Kesehatan, 16-25.

Montgomery, D. C. (2009). Statistical Quality Control: A Modern Introduction. United States: Jhon Wiley and Sons, Inc.

Nabila, K., \& Rochmoeljati. (2020). Analisis Pengendalian Kualitas Menggunakan Metode Six Sigma dan Perbaikan dengan Kaizen (Studi Kasus: PT. XYZ). Juminten: Jurnal Manajemen Industri dan Teknologi, 116-127.

Purnomo, H. (2004). Pengantar Teknik Industri. Yogyakarta: Graha Ilmu.

Purwanto, A., Mirawati, S. M., Arthawati, S. N., Radyawanto, A. S., Rusdianto, B., Haris, M., . . . Yunanto, D. A. (2020). Lean Six Sigma Model for Pharmacy Manufacturing: Yesterday, Today and Tomorrow. Sys Rev Pharm: A Multifaceted Review Journal in the Field of Pharmacy, 304313.

Rahayu, P., \& Bernik, M. (2020). Peningkatan Pengedalian Kualitas Produk Roti dengan Metode Six Sigma Menggunakan New \& Old 7 Tools. Jurnal Bisnis \& Kewirausahaan, 128136.

Ridwan, A., Arina, F., \& Permana, A. (2020). Peningkatan Kualitas dan Efisiensi pada Proses Produksi Dunnage Menggunakan Metode Lean 
Jurnal Pendidikan dan Aplikasi Industri (UNISTEK)

Vol. 8 No.1 Februari 2021

p- ISSN : 0126 - 4036

e- ISSN : $2716-0416$

Six Sigma (Studi Kasus di PT. XYZ). Teknika:

Jurnal Sains dan Teknologi, 186-199.

Safrizal, \& Muhajir. (2016). Pengendalian Kualitas dengan Metode Six Sigma. 5(2).

Somadi. (2020). Evaluasi Keterlambatan Pengiriman Barang dengan Menggunakan Metode Six Sigma. Jurnal Logistik Indonesia, 81-93.

Wisnu, A. P. (2013). Quality Control: Panduan Penerapan Teknis. Bekasi: Wishnu AP \& Partners. 